\title{
Selected elements of a new method of induction motor efficiency determination
}

\author{
K. DABALA* \\ Electrotechnical Institute, Department of Electric Drives, 28 Pozaryskiego St., 04-703 Warsaw, Poland
}

\begin{abstract}
This paper presents the results of estimating method of the energy consumed by induction motors and the legal situation concerning the efficiency of electrical motors in the European Union. Three elements of a new method of induction motor efficiency determination are described: methodology of taking into account the influence of non-sinusoidal voltage and the voltage unbalance on the motor efficiency and the application of the interval arithmetic in order to determine the border error of the induction motor efficiency. It is proved that the middle of efficiency interval for the direct method of efficiency determination is always equal to or higher than the measurement result and the radius of interval is longer than the border error.
\end{abstract}

Key words: electrical machines, induction motors, efficiency under voltage distortions, intervals in efficiency determination methods.

\section{Introduction}

In July 2009, the European Commission accepted the Regulation No. 640/2009 [1] on implementing the Directive of 2005/32/EC of the European Parliament and of the Council concerning requirements of the eco-project for electrical motors. It means that legally sanctioned requirements concerning the energy efficiency of 3-phase, 2-, 4- and 6-pole induction motors were implemented on the EU market. Enforced legal documents match the energy saving policy adopted by the EU.

The regulation concerning this group of electric motors (3-phase induction motors) is justified. According to [2, 3] and to the author's estimation, 3-phase induction motors with the power in range of $0.75-375 \mathrm{~kW}$ consume about $26 \%$ of the world's electric energy delivered to recipients, which is equal to about $57 \%$ of the power consumption through all electric motors in the world, however 3-phase induction motors with power in range of $0.75-750 \mathrm{~kW}$ consume about $32 \%$ of the world's electric energy delivered to recipients, which is equal to about $70 \%$ of the power consumption by all electric motors in the world.

Considering the above data, it is possible to state that this group of motors offers potential savings of electric energy. Therefore, the Regulation implements the obligation of delivering more and more high-efficient motors to the market (a growing number of classes of the IE efficiency). Simultaneously, determining the method of appointing the efficiency as a "reliable, accurate and reproducible method, which takes into account the generally recognized state-of-the-art methods, and whose results are deemed to be of low uncertainty" is necessary. Hence, there is a need to create new and improve the old methods of determining efficiency in induction motors. These

*e-mail: k.dabala@iel.waw.pl methods will allow for determining efficiency increasingly similar to the real efficiency.

In the present article, three elements of the new method of induction motor efficiency determination were described:

- methodology of taking into account the influence of voltage distortion on the efficiency,

- methodology of taking into account the influence of voltage unbalance on the efficiency,

- application of the interval arithmetic to determine the border error of induction motor efficiency.

Other elements of the presented method were described, among others, in the previous works [4-7].

\section{Methodology of taking into account the influence of the voltage distortion on motor efficiency}

Supply voltage from the grid as well as from devices suppling the motor in the laboratory under tests (e.g. from power converters, induction regulators, synchronous and asynchronous generators) can be non-sinusoidal. Such voltage can be expressed as the Fourier series:

$$
u(t)=\sqrt{2}\left[U_{1} \sin \omega_{1} t+\sum_{k=2}^{\infty} U_{k} \sin \left(k \omega_{1} t+\phi_{k}\right)\right]
$$

and current:

$$
i(t)=\sqrt{2}\left[I_{1} \sin \omega_{1} t+\sum_{k=2}^{\infty} I_{k} \sin \left(k \omega_{1} t+\theta_{k}\right)\right],
$$

where $U_{1}, I_{1}$ are rms values of voltage and current fundamental harmonics; $U_{k}, I_{k}$ are rms values of voltage and current $k^{\text {th }}$ harmonics; $\phi_{k}, \theta_{k}$ are phase angles of voltage and current $k^{\text {th }}$ harmonics; $\omega_{1}=2 \pi f_{1}$ denotes angular frequency of the fundamental harmonic. 
The slip of rotor corresponding to the $k^{\text {th }}$ harmonic of stator current $[11,12]$ is expressed as:

$s_{k}=\frac{k n_{s} \mp(1-s) n_{s}}{k n_{s}}=\frac{k \mp(1-s)}{k}=1 \mp \frac{1-s}{k}$,

where $n_{s}$ is synchronous speed of the fundamental harmonic; $s$ is the slip of rotor corresponding to the fundamental harmonic of stator current. The "-" sign refers to harmonics rotating according to the $1^{\text {st }}$ harmonic, and the "+" signs refers to harmonics rotating opposite to the $1^{\text {st }}$ harmonic.

The frequency of $k^{\text {th }}$ harmonic of the stator current is equal to $k f_{1}$ and $k^{\text {th }}$ harmonic of the rotor current is equal $k f_{1} s_{k}$. Synchronous speed of the $k^{\text {th }}$ harmonic corresponding to the frequency $k f_{1}$ is equal $k n_{s}$, where

$$
n_{s}=\frac{60 f_{1}}{p}
$$

and $p$ is the $p_{\text {number of pole pairs. }}$

Voltage harmonics $1,4,7,10,13 \ldots[3 n+1]$ contribute to a rotating magnetomotive force in the direction of motion and positive torque, whereas the $2,5,8,11,14 \ldots[3 n+2]$ contribute to a rotating magnetomotive force in the direction opposite of motion and negative torque. The $3,6,9,12,15 \ldots[3 n+3]$ produce non-rotating magnetomotive force and therefore do not contribute to electromagnetic torque generation $(n=0,1,2, \ldots)$.

The influence of supply voltage on the motor characteristics is presented in [8]. The method of analysis of the motor supplied with that voltage was suggested, e.g. in [9] and [10]. It relies on the superposition of individual effects of the harmonic action, so it does not take the nonlinearity into account. Partly the effect of saturation is being taken into account in [11] by implementing the coefficient modifying the magnetizing reactance.

We assume that the motor is symmetrical and further considerations are kept for the equivalent circuit of single phase of the motor. The circuit is typical (T), in addition, for higher harmonics a magnetizing branch is neglected, since its value $\left(k X_{m}\right)$ is much higher than the rotor leakage impedance. For a similar reason, resistances representing losses in the core and mechanical are neglected for both fundamental and higher harmonics. The $k^{\text {th }}$ current harmonic is then given as:

$$
I_{k}=\frac{U_{k}}{\sqrt{\left(R_{s k}+R_{r k} / s_{k}\right)^{2}+\left(X_{s k}+X_{r k}\right)^{2}}},
$$

where $R_{s k}$ and $R_{r k}$ are the stator and rotor resistances; $X_{s k}$ and $X_{r k}$ are the stator and rotor reactances for the $k^{\text {th }}$ harmonic. The total harmonic current is defined as:

$$
I_{h}=\sqrt{\sum_{k=2}^{n} I_{k}^{2}} .
$$

Based on [11], and neglecting the skin effect losses from individual harmonics in the winding of the stator, we can calculate harmonic losses in stator as:

$$
P_{w s h}=R_{s} I_{h}^{2}
$$

and in the rotor, skin effect should be taken into account, so losses due to each harmonic must be calculated individually and added as:

$$
P_{w r h}=\sum_{k=2}^{n} R_{r k} I_{r k}^{2}
$$

In [11] approximate formulas for estimating the core losses and stray-load losses in motor caused by voltage distortion are also given.

Other works, e.g. [19, 20], present analytical methods of slot leakage inductance for 3-phase induction motor winding and others inductances. These methods can be used for calculation of stator and rotor reactances (i.e. $X_{s k}$ and $X_{r k}$ ) for higher harmonics.

The author of this paper calculated the decrease of efficiency by higher harmonics for motor rated power $P_{\mathrm{N}}=15 \mathrm{~kW}$, rated voltage $U_{\mathrm{N}}=380 \mathrm{~V}$. The method described in this chapter was used. The results are presented in Fig. 1.

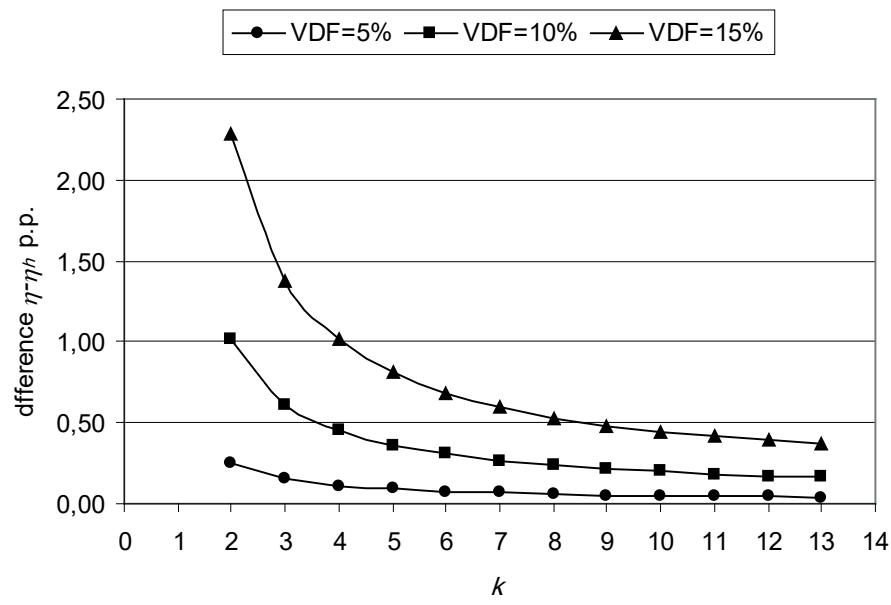

Fig. 1. The difference between the rated efficiency $h$ and efficiency $h_{h}$ calculated with high harmonics $k$ for different values of VDF (Voltage Distortion Factor, VDF $=U_{k} / U_{1} \times 100 \%$, p.p. means percentage points)

From the results one can see that the function $h-h_{h}=\mathrm{f}(k)$ is a decreasing function. One can also see a considerable influence of the harmonic amplitude on losses, e.g. for the $2^{\text {nd }}$ harmonic difference between $5 \%$ and $15 \%$, reducing the efficiency even about 2 percentage points in this motor.

In [12], authors presented interesting results of laboratory tests of $2.2 \mathrm{~kW}$ motor supplying from the source with the differently distorted voltage (harmonic from 1 to 13). The largest differences are appearing in the efficiency for $2^{\text {nd }}$ harmonic and are equal to 2.12 percentage points, 3.48 percentage points, 6.09 percentage points (respectively for VDF (Voltage Distortion Factor) $=5 \%, 10 \%, 15 \%)$. Harmonic order does not alwaysdetermine the size of additional losses. For example for VFD $=10 \%$ order harmonic causing losses from largest 
to smallest is as follows: $2,4,5,7,3,8,6,10,11,9,12$, and 13. One can also see a considerable influence of the harmonic amplitude on losses, e.g. for $2^{\text {nd }}$ harmonic difference between $5 \%$ and $15 \%$ reducing the efficiency even by 3.97 percentage points in this motor.

\section{Methodology of taking into account the influence of the voltage unbalance on motor efficiency}

The 3-phase unbalanced voltage with rms complex values $U_{A}$, $U_{B}, U_{C}$ can be represented by three systems of 3-phase symmetrical voltages [13]: positive-, negative- and zero-sequence:

\begin{tabular}{|l|l|l|l|}
\hline positive: & $\underline{U}_{A 1}$ & $\underline{U}_{B 1}=a^{2} \underline{U}_{A 1}$ & $\underline{U}_{C 1}=a \underline{U}_{A 1}$ \\
\hline negative: & $\underline{U}_{A 2}$ & $\underline{U}_{B 2}=a \underline{U}_{A 2}$ & $\underline{U}_{C 2}=a^{2} \underline{U}_{A 2}$ \\
\hline zero: & $\underline{U}_{A 0}$ & $\underline{U}_{B 0}=\underline{U}_{A 0}$ & $\underline{U}_{C 0}=\underline{U}_{A 0}$ \\
\hline
\end{tabular}

Where:

$a=-\frac{1}{2}+\mathrm{j} \frac{\sqrt{3}}{2}=\mathrm{e}^{\mathrm{j} \frac{2 \pi}{3}}$,

$a^{2}=-\frac{1}{2}-\mathrm{j} \frac{\sqrt{3}}{2}=\mathrm{e}^{\mathrm{j} \frac{4 \pi}{3}}=\mathrm{e}^{-\mathrm{j} \frac{2 \pi}{3}}$,

Subscript: 1 - positive component

$$
\begin{aligned}
& 2 \text { - negative component } \\
& 0 \text {-zero component }
\end{aligned}
$$

$U_{A i}, U_{B i}, U_{C i}-$ rms complex values of symmetrical component $i(i \in\{1,2,0\})$ appropriately to phase $A, B$ i and $C$.

The method of symmetrical components applies linear transformation to the unbalanced systems of voltages resulting in three symmetrical systems of voltages. So we replace the unbalanced power source with three balanced sources and by applying the superposition principle, we calculate the currents for every balanced system of voltages. Next, we add calculated currents excited by every source independently and we receive the resultant flow.

Since phase shifts between phase vectors of every balanced system (9-11) are well-known, there is no need to determine 9 voltages (9-11). It will be sufficient to determine the basic vector of every system, that is 3-phase vectors. Basic phase vectors of every symmetrical system related, e.g. to the phase $A$ and marked appropriately $\underline{U}_{A 0}, \underline{U}_{A 1}, \underline{U}_{A 2}$ will be called symmetrical components: zero-, positive- and negative-sequence.

Unbalanced voltage of every phase has to be equal to the sum of appropriate symmetrical components:

$$
\begin{aligned}
& \underline{U}_{A}=\underline{U}_{A 0}+\underline{U}_{A 1}+\underline{U}_{A 2} \\
& \underline{U}_{B}=\underline{U}_{A 0}+a^{2} \underline{U}_{A 1}+a \underline{U}_{A 2} \\
& \underline{U}_{C}=\underline{U}_{A 0}+a \underline{U}_{A 1}+a^{2} \underline{U}_{A 2},
\end{aligned}
$$

or presented in the matrix form where:

$$
\mathbf{U}=\mathbf{S U}_{\mathrm{S}}
$$

$$
\begin{aligned}
& \mathbf{U}=\left[\begin{array}{l}
\underline{U}_{A} \\
\underline{U}_{B} \\
\underline{U}_{C}
\end{array}\right] \quad \text { - matrix of unbalanced voltages } \\
& \mathbf{U}_{S}=\left[\begin{array}{l}
\underline{U}_{A 0} \\
\underline{U}_{A 1} \\
\underline{U}_{A 2}
\end{array}\right] \quad \begin{array}{c}
\text { matrix of voltages of symmetrical } \\
\text { components }
\end{array} \\
& \mathbf{S}=\left[\begin{array}{ccc}
1 & 1 & 1 \\
1 & a^{2} & a \\
1 & a & a^{2}
\end{array}\right]-\text { Smatrix of transformation }
\end{aligned}
$$

Usually, it is the determination of symmetrical components in asymmetrical system that characterizes the problem to be solved, as opposed to (15). For this reason we multiply both sides of equation (15) by reverse matrix $\mathbf{S}^{-1}$

and we obtain

$$
\mathbf{S}^{-1} \mathbf{U}=\mathbf{S}^{-1} \mathbf{S U}_{S}
$$

$$
\mathbf{U}_{S}=\mathbf{S}^{-1} \mathbf{U}
$$

where

$$
\mathbf{S}^{-1}=\frac{1}{3}\left[\begin{array}{ccc}
1 & 1 & 1 \\
1 & a & a^{2} \\
1 & a^{2} & a
\end{array}\right],
$$

and

$$
\begin{aligned}
& \underline{U}_{A 0}=\frac{1}{3}\left(\underline{U}_{A}+\underline{U}_{B}+\underline{U}_{C} .\right. \\
& \underline{U}_{A 1}=\frac{1}{3}\left(\underline{U}_{A}+a \underline{U}_{B}+a^{2} \underline{U}_{C}\right) \\
& \underline{U}_{A 2}=\frac{1}{3}\left(\underline{U}_{A}+a^{2} \underline{U}_{B}+a \underline{U}_{C}\right),
\end{aligned}
$$

The author of this paper has proposed to present the system of supply voltages as:

$$
\begin{aligned}
& \underline{U}_{A}=k U \mathrm{e}^{\mathrm{j}(0+\alpha)} \\
& \underline{U}_{B}=l U \mathrm{e}^{-\mathrm{j}\left(\frac{2 \pi}{3}+\beta\right)} \\
& \underline{U}_{C}=m U \mathrm{e}^{\mathrm{j}\left(\frac{2 \pi}{3}+\gamma\right)},
\end{aligned}
$$

where

$k, l, m \in \mathbf{R}^{+} \quad$ are unbalanced factors of rms voltages

$\alpha, \beta, \gamma \in\left(-\frac{2 \pi}{3} ; \frac{2 \pi}{3}\right) \quad \begin{aligned} & U \text { in appropriate phases, } \\ & \text { are the phases which cause the phase un- }\end{aligned}$ balance of voltage system (20). 
It stems from equation (20) that the following system coordinates apply on the complex surface:

- real value axis with respect to phase $A$, e. g. directed vertically to the top,

- complex value axis rotated $90^{\circ}$ in counter-clockwise direction, e. g. directed horizontally to the left side.

Let us determine the symmetrical components for the system (20), taking into consideration $(19,12-13)$ :

$$
\begin{aligned}
& \underline{U}_{A 0}=\frac{1}{3} U\left(k \mathrm{e}^{\mathrm{j} \alpha}+l \mathrm{e}^{-\mathrm{j}\left(\frac{2 \pi}{3}+\beta\right)}+m \mathrm{e}^{\mathrm{j}\left(\frac{2 \pi}{3}+\gamma\right)}\right. \\
& \underline{U}_{A 1}=\frac{1}{3} U\left(k \mathrm{e}^{\mathrm{j} \alpha}+l \mathrm{e}^{-\mathrm{j} \beta}+m \mathrm{e}^{\mathrm{j} \gamma}\right) \\
& \underline{U}_{A 2}=\frac{1}{3} U\left(k \mathrm{e}^{\mathrm{j} \alpha}+l \mathrm{e}^{-\mathrm{j}\left(-\frac{2 \pi}{3}+\beta\right)}+m \mathrm{e}^{\left.\mathrm{j}\left(-\frac{2 \pi}{3}+\gamma\right)\right)} .\right.
\end{aligned}
$$

It is necessary to remind that $\underline{U}_{A 0}(21)$ denotes complex rms value of the zero-sequence symmetrical component associated with the phase $A$. The other phase vectors of the zero-sequence symmetrical systems $\left(\underline{U}_{B 0}, \underline{U}_{C 0}\right)$ are easy to determine because there are known the phase angles among them.

Similar remark concerns $\underline{U}_{A 1}$ and $\underline{U}_{A 2}$ in equations (22-23).

The above work concerns different phase vectors, e. g. unbalanced system of line currents or phase currents, unbalanced system of impedance - it is enough then to replace $\underline{U}_{A 1}$ in the above equations by appropriate symbol, i. e. $\underline{I}_{A B}, \underline{I}_{A}, \underline{Z}_{A B}, \underline{Z}_{A}$.

Let us assume that the motor is symmetrical with stator winding connected in star. Unbalanced system of line voltages $\underline{U}_{A B}, \underline{U}_{B C}, \underline{U}_{C A}$ is split to positive- and negative-sequence systems by (19). Zero-sequence system in this case equals 0 .

Hence, we get

$$
\begin{aligned}
& \underline{U}_{A B 1}=\frac{1}{3}\left(\underline{U}_{A B}+a \underline{U}_{B C}+a^{2} \underline{U}_{C A}\right) \\
& \underline{U}_{A B 2}=\frac{1}{3}\left(\underline{U}_{A B}+a^{2} \underline{U}_{B C}+a \underline{U}_{C A}\right)
\end{aligned}
$$

and

$$
\begin{aligned}
& \underline{U}_{B C 1}=a^{2} \underline{U}_{A B 1} \\
& \underline{U}_{B C 2}=a \underline{U}_{A B 2} \\
& \underline{U}_{C A 1}=a \underline{U}_{A B 1} \\
& \underline{U}_{C A 2}=a^{2} \underline{U}_{A B 2}
\end{aligned}
$$

that is two symmetrical systems: positive- $\underline{U}_{A B 1}, \underline{U}_{B C 1}, \underline{U}_{C A 1}$ and negative-sequence $\underline{U}_{A B 2}, \underline{U}_{B C 2}, \underline{U}_{C A 2}$ components of line voltages.

Because of the motor winding symmetry, in the following considerations we are limited to only one phase. If voltages $\underline{U}_{A B 1}=U_{A B 1} \mathrm{e}^{\mathrm{j} \alpha}$ and $\underline{U}_{A B 2}=U_{A B 2} \mathrm{e}^{\mathrm{j} \beta}$ then positive- and negative-sequence components of phase voltage are equal

$$
\begin{aligned}
& \underline{U}_{A 1}=\frac{U_{A B 1}}{\sqrt{3}} \mathrm{e}^{\mathrm{j}\left(\alpha-\frac{\pi}{6}\right)}=\frac{U_{A B 1}}{\sqrt{3}} \mathrm{e}^{\mathrm{j}\left(\alpha-30^{\circ}\right)} \\
& \underline{U}_{A 2}=\frac{U_{A B 2}}{\sqrt{3}} \mathrm{e}^{-\mathrm{j}\left(\beta+\frac{\pi}{6}\right)}=\frac{U_{A B 2}}{\sqrt{3}} \mathrm{e}^{-\mathrm{j}\left(\beta+30^{\circ}\right)}
\end{aligned}
$$

The additional losses caused by negative-sequence system are expressed as [14]:

$$
P_{a d d 2}=3\left(\frac{U_{A 2}}{Z_{2}}\right)^{2}\left[\left(Z_{2} \cos \theta_{A 2}\right)(2-s)-(1-s) R_{s}\right] \text {, }
$$

where $\underline{Z}_{2}-$ rms complex value of negative-sequence component of impedance.

It can be determined experimentally for the motor by RRT (Reverse Rotation Test) under balanced supply and rated current. If the measurements of phase power $P_{A 2}$, phase current $I_{A 2}$ and phase voltage $U_{A 2}$ are known,

then $\underline{Z}_{2}=\frac{U_{A 2}}{I_{A 2}} \mathrm{e}^{\mathrm{j} \theta_{A 2}}$ and $\cos \theta_{A 2}=\frac{P_{A 2}}{U_{A 2} I_{A 2}}$.

$R_{S}$ - phase resistance of stator winding.

Another way of $\underline{Z}_{2}$ determination is the algorithm presented in [14].

In the case, when the motor has the winding connected in the delta, there is an additional zero-sequence component which flows in the delta, increasing the losses. In [15] both experimental and calculated ways to determine zero-sequence currents and impedance are presented.

The author of this paper calculated the decrease of efficiency under voltage unbalance for motor rated power $P_{\mathrm{N}}=15 \mathrm{~kW}$, rated voltage $U_{\mathrm{N}}=380 \mathrm{~V}$. The method described in this chapter was used. Two cases were taken into consideration:

- only voltage rms value unbalance in three phases for different VUF (Voltage Unbalance Factor, VUF $=U_{2} /$ $U_{1} \times 100 \%, U_{2}$ - negative-sequence component, $U_{1}$ - positive-sequence component) (Fig. 2),

- only voltage angle unbalance in three phases, (Fig. 3).

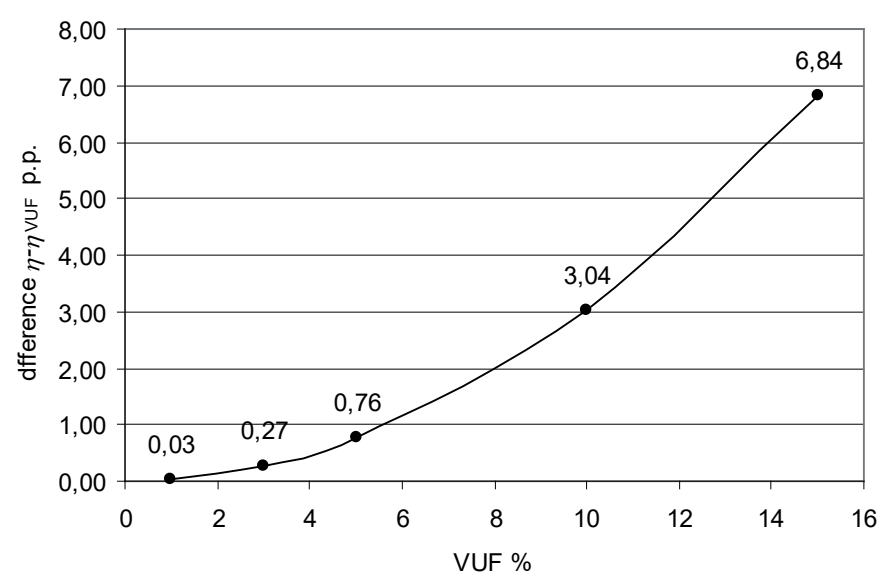

Fig. 2. The difference between the rated efficiency $h$ and efficiency $h_{\mathrm{VUF}}$ calculated for different values of VUF (p.p. means percentage points) 


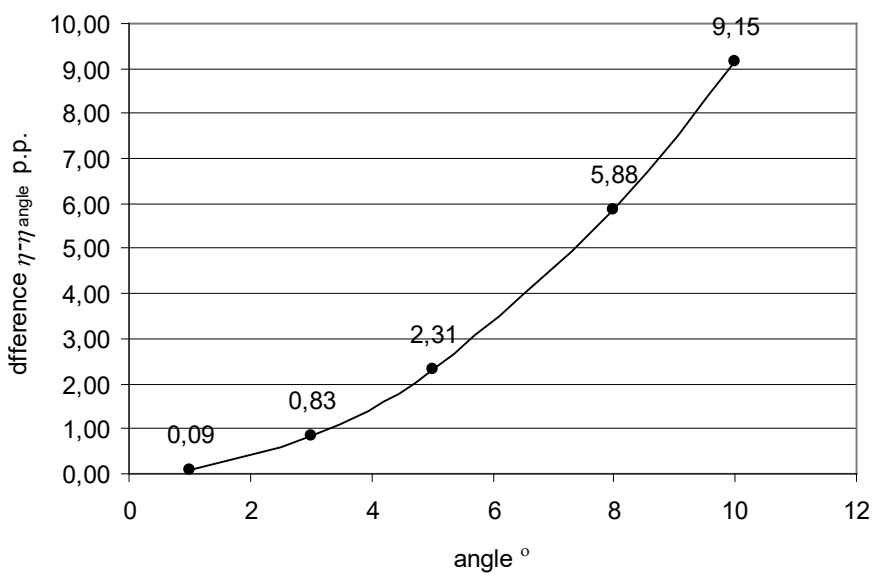

Fig. 3. The difference between the rated efficiency $h$ and efficiency $h_{\text {angle }}$ calculated for different values of angle unbalance (p.p. means percentage points)

Even an insignificant asymmetry of voltage rms value, e.g. $5 \%$, leads to decreasing efficiency by about 0.8 percentage points. Greater, e.g. 10\%, leads to decreasing efficiency of about 3 percentage points. In the case of voltage angle unbalance, the difference in efficiency is significant, too, e.g. for $5^{\circ}$ it amounts to 2.31 percentage points and for $8^{\circ}-$ even 5.88 percentage points in this motor.

In [17] very interesting results of tests of $2.2 \mathrm{~kW}$ motor supplied in different asymmetrical conditions were presented. Maximal difference of motor efficiency (3.27 percentage points) appeared when the asymmetry occurred in all 3 phases and the rms values were decreased (as compared to rated values). When asymmetry of 1 phase is only $6.9^{\circ}$, the difference of efficiency is equal to 0.76 percentage points, while asymmetry of 2 phases are respectively $8,1^{\circ}$ and $4^{\circ}$ the difference of efficiency is equal to even 1.55 percentage points. Thus, the conclusion can be drawn that even relatively low asymmetry causes motor efficiency reduction.

\section{Determination of the border error using the interval arithmetic for direct method of induction motor efficiency calculation}

The direct method of efficiency determination consists of measurements of output power $P_{\text {out }}$ and input power $P_{\text {in }}$

$$
\eta=\frac{P_{\text {out }}}{P_{\text {in }}} .
$$

Since output power $P_{\text {out }}$ is determined based on measurements of the motor torque $M$ in $\mathrm{Nm}$ and rotational speed $n$ in $\mathrm{rev} / \mathrm{min}$, the efficiency formula is $\left(P_{\text {in }}\right.$ in $\left.\mathrm{W}\right)$ :

$$
\eta=\frac{\pi}{30} \frac{M \cdot n}{P_{\text {in }}} \text {. }
$$

Based on former works $[7,18]$, it can be stated that:
- the middle of the interval corresponds to the result of the measurement,

- the radius of the interval corresponds to the border error.

However, the resultant quantities received from calculations based on the specific processing function by intervallic and classic methods do not have to be identical. In this chapter, the author of the article conducted an analysis of these relations.

4.1. Definition of interval. For every pair of real numbers $\mathrm{a}^{-}$, $\mathrm{a}^{+}$, where $\mathrm{a}^{-} \leq \mathrm{a}^{+}$, a set of real numbers $\mathrm{a}^{-} \leq \mathrm{x} \leq \mathrm{a}^{+}$is named interval.

$$
[\mathrm{a}]=\left[\mathrm{a}^{-} ; \mathrm{a}^{+}\right]=\left\{\mathrm{x} \in \mathrm{R} \mid \mathrm{a}^{-} \leq \mathrm{x} \leq \mathrm{a}^{+}\right\} .
$$

In the case of the processing function (34), the middle of the interval $\eta_{\text {mid }}$ is

$$
\begin{aligned}
\eta_{\text {mid }} & =\frac{\pi}{30} \frac{\frac{M^{-} n^{-}}{P_{\mathrm{in}}^{+}}+\frac{M^{+} n^{+}}{P_{\mathrm{in}}^{-}}}{2}= \\
= & \frac{\pi}{30} \frac{1}{2} \frac{P_{\mathrm{in}}^{-} M^{-} n^{-}+P_{\mathrm{in}}^{+} M^{+} n^{+}}{P_{\mathrm{in}}^{+} P_{\mathrm{in}}^{-}},
\end{aligned}
$$

while in the classic method the result of the measurement is

$$
\begin{aligned}
\eta & =\frac{\pi}{30} \frac{\frac{M^{+}+M^{-}}{2} \frac{n^{+}+n^{-}}{2}}{\frac{P_{\mathrm{in}}^{+}+P_{\mathrm{in}}^{-}}{2}}= \\
& =\frac{\pi}{30} \frac{1}{2} \frac{M^{+} n^{+}+M^{+} n^{-}+M^{-} n^{+}+M^{-} n^{-}}{P_{\mathrm{in}}^{+}+P_{\mathrm{in}}^{-}},
\end{aligned}
$$

where: $M^{+}, M^{-}, n^{+}, n^{-}, P_{i n}^{+}, P_{i n}^{-},-$interval ends of torque [M], rotational speed $[n]$, and input power $\left[P_{\text {in }}\right]$, which are also the approximate border errors of these quantities.

4.2. Theorem. Coefficient $b$ in (38) being a quotient of the middle of the interval (36) and the result of measurement (37) is equal to or greater than 1.

$$
\begin{aligned}
b= & \frac{P_{\mathrm{in}}^{-} P_{\mathrm{in}}^{+} M^{+} n^{+}+P_{\mathrm{in}}^{-} P_{\mathrm{in}}^{+} M^{-} n^{-}+P_{\mathrm{in}}^{-2} M^{-} n^{-}+}{P_{\mathrm{in}}^{-} P_{\mathrm{in}}^{+} M^{+} n^{+}+P_{\mathrm{in}}^{-} P_{\mathrm{in}}^{+} M^{-} n^{-}+P_{\mathrm{in}}^{-} P_{\mathrm{in}}^{+} M^{+} n^{-}+} \\
& \frac{+P_{\mathrm{in}}^{+2} M^{+} n^{+}}{+P_{\mathrm{in}}^{-} P_{\mathrm{in}}^{+} M^{-} n^{+}}
\end{aligned}
$$

4.3. Proof. Let us show (38) in the following form:

so

$$
b=\frac{A+B+C+D}{A+B+E+F} \geq 1 \text { i. e. } C+D \geq E+F,
$$

$P_{\text {in }}^{-2} M^{-} n^{-}+P_{\text {in }}^{+2} M^{+} n^{+}-P_{\text {in }}^{-} P_{\text {in }}^{+} M^{+} n^{-}-P_{\text {in }}^{-} P_{\text {in }}^{+} M^{-} n^{+} \geq 0$ 
After transformations we get

$$
\frac{M^{+}}{M^{-}} \frac{\frac{P_{\text {in }}^{+}}{P_{\text {in }}^{-}} n^{+}-n^{-}}{n^{+}-\frac{P_{\text {in }}^{-}}{P_{\text {in }}^{+}} n^{-}} \geq 1,
$$

because

$\frac{M^{+}}{M^{-}} \geq 1$ from the definition of interval (35), so

$$
\frac{\frac{P_{\text {in }}^{+}}{P_{\text {in }}^{-}} n^{+}-n^{-}}{n^{+}-\frac{P_{\text {in }}^{-}}{P_{\text {in }}^{+}} n^{-}} \geq 1 .
$$

After transformations we obtain

$$
\left(P_{\text {in }}^{+}-P_{\text {in }}^{-}\right)\left(\frac{n^{+}}{P_{\text {in }}^{-}}-\frac{n^{-}}{P_{\text {in }}^{+}}\right) \geq 0,
$$

because

$P_{i n}^{+}-P_{i n}^{-} \geq 0$ from the definition of interval (35), so

$$
\frac{n^{+}}{n^{-}} \frac{P_{\text {in }}^{+}}{P_{\text {in }}^{-}} \geq 1
$$

$\frac{n^{+}}{n^{-}} \geq 1$ and $\frac{P_{\text {in }}^{+}}{P_{\text {in }}^{-}} \geq 1$ from the definition of interval (35),

so indeed, $\frac{n^{+}}{n^{-}} \frac{P_{\mathrm{in}}^{+}}{P_{\mathrm{in}}^{-}} \geq 1$ and it is proved that $b \geq 1$.

Coefficient $b$ is equal to 1 only when the intervals $\left[P_{\text {in }}\right]$, $[M]$ and $[n]$ have the radius equal 0 , i. e. $\left(P_{i n}^{-}=P_{i n}^{+}, M^{-}=M^{+}\right.$, $\left.n^{-}=n^{+}\right)$. Coefficient $b$ in (38), being a quotient of the middle of the interval (36) and of result of the measurement (37) is equal to or greater than 1. It means that for function (34), the middle of the interval is always equal to or higher than the result of the measurement.

The radius of interval for function (34) can be shown as:

$\operatorname{rad}([\eta])=\eta_{\text {mid }} \frac{\delta_{n}+\delta_{M}+\delta_{P_{\text {in }}}+\delta_{n} \cdot \delta_{M} \cdot \delta_{P_{\text {in }}}}{1-\delta_{P_{\text {in }}}^{2}}$,

where $\delta_{n}, \delta_{M}, \delta_{P_{i}}$ are relative border errors of individually measured quantities, while absolute border error of efficiency $\Delta_{\eta}$

$$
\Delta_{\eta}=\eta\left(\delta_{M}+\delta_{n}+\delta_{P_{i n}}\right)
$$

From comparing formulas (39) and (40) it results that the radius of the interval for function (34) is higher than the border error, since the relative error determined for the interval is bigger and the middle of the interval is greater than the result of the measurement. It is worth noticing, that in (39) omitting the product of border errors and the square of the border error of the input power as negligibly small, one obtains formula for the relative error border of efficiency the same as (40).

The author of this paper calculated the radius of the interval and the border error as well as the middle of the interval and took the result of the measurement for motor rated power $P_{\mathrm{N}}=75 \mathrm{~kW}$ :

- radius $=0.586148 \%$

- border error $=0.586147 \%$

- middle $=95.063998 \%$

- result $=95.063364 \%$.

One can see that the radius of the interval is higher than the border error and the middle of the interval is higher than the result of the measurement. Practically, the efficiency results obtained with different methods are the same, i.e. $95.1 \pm 0.6 \%$.

\section{Conclusion}

In this paper, methodologies of determining the influence of the supply voltages distortions (non-sinusoidal and unbalanced waveforms) on the induction motor efficiency and determination of the border error with intervallic arithmetic in the direct method of efficiency determination were described.

It was proved that the middle of the interval was in case of the direct method of the efficiency determination is always equal to or greater than the result of the measurement, whereas radius of the interval is longer than the border error.

Described elements of the new method of efficiency determination are supposed to contribute to the improvement of efficiency determination of induction motors, allowing to determine efficiency as close to the real motor efficiency as possible.

\section{REFERENCES}

[1] "COMMISSION REGULATION (EC) No 640/2009 of 22 July 2009 implementing Directive 2005/32/EC of the European Parliament and of the Council with regard to ecodesign requirements for electric motors", L191, 26-34 (2009).

[2] A.T. Almeida, H. Faulkner, J.Fong, and K. Jugdoyal, "EuPLot-30-Task-2-5-Jun-2012-Draft.pdf”, http://www.eco-motorsdrives.eu/Eco/Documents files/EuP-Lot-30-Task-2-5-Jun-2012Draft.pdf, Coimbra, (2012).

[3] P. Waide and C.U. Brunner, "Energy efficiency policy opportunities for electric motor driven systems", International Energy Agency, Paris, (2011) http://www.iea.org/publications/freepublications/publication/EE_for_ElectricSystems.pdf.

[4] M. Dąbrowski and K. Dąbała, "Accuracy of the efficiency determination of the induction motor depending on the accuracy of setting the supply voltage", Prace Naukowe Instytutu Maszyn, Napędów i Pomiarów Elektrycznych Politechniki Wrocławskiej $n r$ 48, seria Studia i Materiaty nr 20, 86-96 (2000), (in Polish).

[5] K. Dąbała, "The influence of the ambient temperature on the induction squirrel-cage motor efficiency", Proceedings-summaries of 39th International Symposium on Electrical Machines, 65-65 (2003), (in Polish).

[6] K. Dąbała, "Current study concerning induction motor efficiency and its experimental determination", Prace IEl 223, 43-56 (2005). 
[7] K. Dąbała, "Research into possibilities of interval arithmetic application to induction motor efficiency determination", Zeszyty Problemowe-Maszyny Elektryczne 84, 39-44 (2009), (in Polish).

[8] J.R. Linders, "Effects of Power Supply Variations on AC Motor Characteristics", IEEE Trans. on Industry Applications 4, 383-400 (1972).

[9] P.G. Cumming, "Estimating Effects of System Harmonics on Losses and Temperature Rise of Squirrel-Cage Motors", IEEE Trans. on Industry Applications 6, 1121-1126 (1986).

[10] E.A. Klingshirn, and H.E. Jordan, "Polyphase Induction Motor Performance and Losses on Nonsinusoidal Voltage Sources", IEEE Trans. on Power Apparatus and Systems 3, 624-631 (1968).

[11] P.K. Sen, and H.A. Landa, "Derating of Induction Motor Due to Waveform Distortion", IEEE Trans. on Industry Applications 6, 1102-1107 (1990).

[12] Ch-Y. Lee, and W-J. Lee, "Effects of Nonsinusoidal Voltage on the Operation Performance of a Three-Phase Induction Motor" IEEE Trans. on Energy Conversion 2, 193-201 (1999).

[13] S. Bolkowski Linear electric circuits in steady state, WNT, Warszawa, 1974, (in Polish).
[14] J.E. Williams, "Operation of 3-Phase Induction Motors on Unbalanced Voltages", AIEE Trans., Part III-A, Power Apparatus and Systems 73, 125-133 (1986).

[15] K.P. Kovacs, Symmetrical components in alternating current machines, Birkhäuser Verlag, Basel und Stuttgart, 1962, (in German).

[16] Y-J. Wang, "Analysis of Effects of Three-Phase Voltage Unbalanced on Induction Motor with Emphasis on the Angle of the Complex Voltage Unbalanced Factor", IEEE Trans. on Energy Conversion 3, 270-275 (2001).

[17] Ch-Y. Lee, "Effects of Unbalanced Voltage on the Operation Performance of a Three-Phase Induction Motor", IEEE Trans. on Energy Conversion 2, 202-208 (1999).

[18] A. Zięba, "Still about the sufficient fat straight: in response to W. Gutowski", Postepy fizyki 3, 1-8 (2003), (in Polish).

[19] J. Staszak, "Determination of slot leakage inductance for threephase induction motor winding using an analytical method", Archives of electrical engineering 4, 569-591 (2013).

[20] T. Śliwiński, Methods of calculation for induction motors. T. 1, Analysis, PWN, Warszawa, 2008, (in Polish). 